\title{
Mobile Shopping and Impulse Buying: Chain Mediation of Flow Experience and Purchase Intention
}

\author{
Liu Lin \\ Wu Han University of Technology, Wu Han, China
}

Keywords: Mobile Shopping; Flow Experience; Purchase Intention; Impulse Purchase; Impulsive Trait.

\begin{abstract}
Because of the current situation of mobile Internet shopping beyond PC shopping, this paper studies the impact of mobile shopping on impulse buying. A chain mechanism model of mobile shopping-flow experience-purchase intention - impulse buying is constructed. This paper uses SPSS to do the multiple regression and Mplus to do the multiple medium tests. There is a chain mediated effect between mobile shopping and impulse purchase.
\end{abstract}

\section{Introduction}

In recent years, the use rate of mobile devices in China has been increasing, and mobile client shopping is popular. The mobile network economic revenue scale (790.74 billion Yuan) exceeded the PC (679.95 billion Yuan) for the first time in 2016.mobile shopping has become the mainstream of online shopping in China. Donthu and Garcia (1999) ${ }^{[1]}$ have confirmed that online shoppers are more impulsive than traditional channel shoppers. Therefore, it is of great practical significance to study the formation mechanism of consumer impulse purchase in mobile shopping to meet the current environment of online shopping from PC to mobile.

\section{Literature Review}

Lu Yi (2015) ${ }^{[2]}$ used the S-O-R model and discusses the relationship between the mobile purchase environment and the consumer's purchase intention. Wang Lanqi (2014) ${ }^{[3]}$ used the flow experience as a mediator variable to study the relationship between website characteristics, consumer personality characteristics and impulsive purchase behavior. Shang Xutong (2016) ${ }^{[4]}$ studied the impulsive trait as an antecedent variable of the flow experience. Wu Xiaomei $(2014)^{[5]}$ studied the impulsive trait as a reverse adjustment variable between the flow experience and the impulse purchase. At present, there are many studies on online flow experience and online purchase intention, flow experience and impulsive purchase behavior. But few studies focus on mobile shopping situation.

\section{Research Design}

\subsection{Assumptions and model}

Based on the research of Lu Yi (2015) this study divides the mobile shopping into convenience, personalization, fun, socialization, instantiation, situationalization. H1: Mobile shopping promote the generation of consumer experience.

The influence of the flow experience dimension on the purchase intention is unconfirmed. H2: The flow experience (pleasantness, focus, loss of time, sense of control, concentration) has a positive impact on mobile shopping purchase intention.

Based on the research of $\mathrm{Wu}$ Xiaomei (2014), we propose H3: The flow experience has a positive impact on the impulse purchase of consumers in the mobile shopping process.

According to the theory of planned behavior, we propose H4: In mobile shopping, impulsive shopping behavior is positively affected by the purchase intention.

Based on the research of Zhang (2006) ${ }^{[7]}$, H5: In mobile shopping, the impulsive trait regulates the relationship between purchase intention and impulsive buying behavior. 
As shown in the model, H6a: The interaction between mobile shopping and impulsive buying behavior. H6b: between the flow experience and the impulse purchase behavior, the purchase intention plays a mediating role; H6c: There is a chain intermediary between the mobile shopping and the impulse purchase.

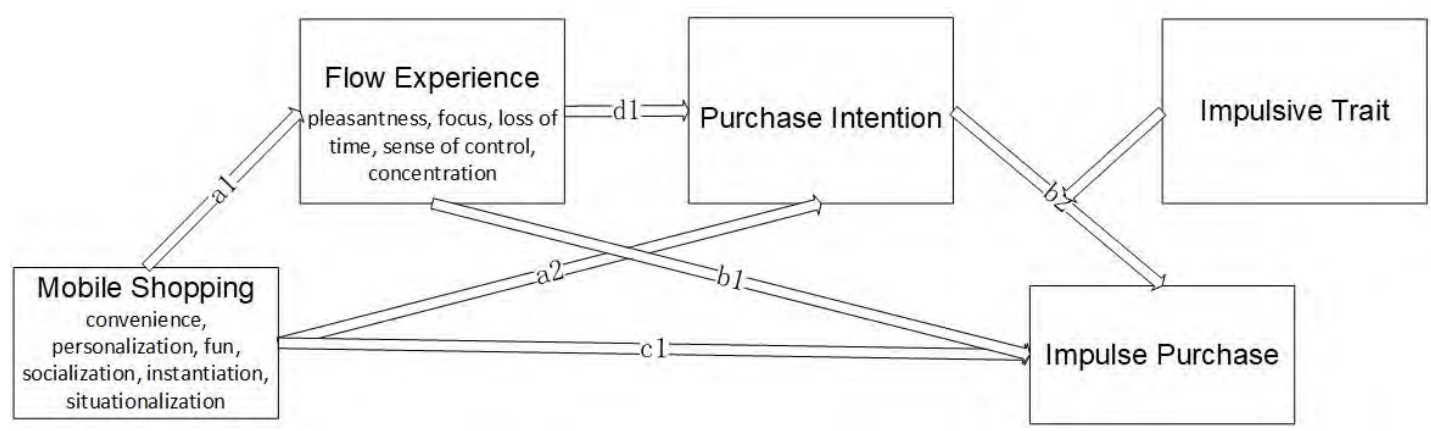

Fig. 1 Theoretical model

\subsection{Questionnaire design and analysis of reliability and validity}

Refer to the mature scale of predecessor research, this study creates a total of 22 items of the questionnaire including the above 5 variables. The data was measured using the Likert five-point scale method. Respondents are invited to fill out the questionnaire online. 324 questionnaires are collected, the valid questionnaires is 236, efficiently achieved $72.83 \%$.The reliability of total 22 items reached 0.909 . The KMO value is 0.875 , which is greater than 0.7. The statistical value of the Bartlett spherical test is less than 0.000 , indicating that the data collected in this questionnaire is highly correlated. Five initial factors initial interpretation level of the five factors reached $73.917 \%$.

\section{Empirical Research}

\subsection{Regression analysis of flow experience as a dependent variable}

M1 examines the relationship of control variables to the flow experience. M2 indicates that the mobile shopping promotes the flow experience. M2_1 to M2_6 reflect the relationship between the six subdivision dimensions and the flow experience. The coefficients are significant. M3_1 to M3_5 examined the effects of control variables and five dimensions of flow experience. M4_1 to M4_5 indicate the impact of mobile shopping on the five dimensions of flow experience. Based on the report in the Table 1, Hypothesis 1 of this study is supported.

\subsection{Regression analysis of purchase intention as a dependent variable}

In the Table 2.M5 examined the effect of control variables on purchase intention, and M6 was the result of mobile shopping input $(\beta=0.56, \mathrm{p}<0.001)$. M6_1 to M6_6 reflect the impact of six dimensions of mobile shopping on purchase intention. M7 input flow experience variable $(\beta=0.44, p<0.01)$. The M7_1 to M7_5 reflect the effect of five dimensions of flow experience on the purchase intention. Therefore, the hypothesis 2 of this paper is supported. M6( $\beta=0.56, \mathrm{p}<0.01)$ and $\mathrm{M} 8(\beta=0.45, \mathrm{p}<0.01)$. According to Baron and Kenny (1986), there is a partial mediation effect between the mobile shopping and the purchase intention. The assumption $6 \mathrm{a}$ is established.

\subsection{Regression analysis of impulsive buying behavior as a dependent variables}

In the Table 3 Impulsive purchase is the ultimate dependent variable. M9 enters the control variable. M10 inputs the impact of mobile shopping( $\beta=0.54, \mathbf{p}<0.01)$. M10_1 to M10_6 report the impact of six dimensions on impulsive purchase. M11 examined the positive and significant relationship between the flow experience and the impulse purchase. M11_1 to M11_5 examined the correlation between the five dimensions of the flow experience and the impulse purchase. Hypothesis 3 is verified.M12 embodies the purchase intention is positive affecting the consumer's impulsive purchase. Hypothesis 4 is established. $\operatorname{M11}(\beta=0.37, \mathrm{p}<0.01)$ and $\mathrm{M} 13(\beta=0.14, \mathrm{p}<0.01)$. We believe purchase intention is partially intermediary and flow experience and impulsive buying behavior. H6b is established.M15 constructs an interaction term between purchase intention and impulsive trait to test the adjustment effect of impulsive traits 
between purchase intention and impulsive purchase. The cross-term of the test results is not significant. This paper assumes that $\mathrm{H} 5$ is not established and the regulatory effect does not exist.

\subsection{Multiple mediation effect test}

H6a and H6b have been validated. This paper uses Mplus to analyze the specific effects and total mediation effects of multiple mediation effect, and writes the bootstrap statement. The proposed mediation analysis program, Boots trap sampling is 5000, setting a 95\% confidence interval. If the interval estimate contains 0 , it means that the mediation is not significant. Results are shown in Table 4 . The $95 \%$ confidence interval of the chain mediation path-the mobile shopping-flow experience-purchase intention-impulse purchase (path A1DA1BA) is [0.001, 0.005], excluding 0. H6c is established.

Table 1 Regression analysis of flow experience as a dependent variable

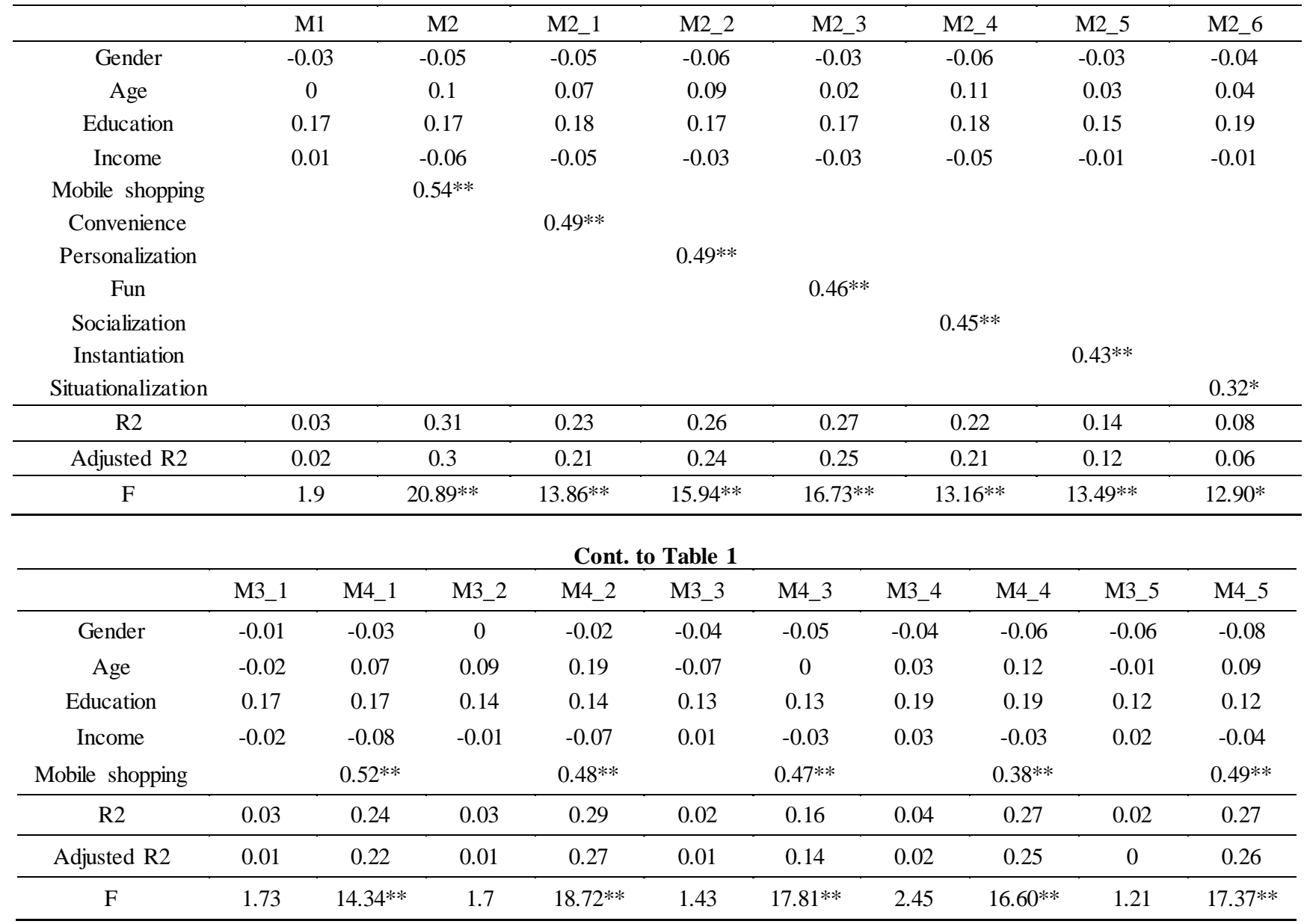

Table 2 Regression analysis of purchase intention as a dependent variable

\begin{tabular}{|c|c|c|c|c|c|c|c|c|}
\hline & M5 & M6 & M6_1 & M6_2 & M6_3 & M6_4 & M6_5 & M6_6 \\
\hline Gender & 0 & -0.02 & -0.03 & -0.03 & 0 & -0.03 & -0.01 & -0.01 \\
\hline Age & 0.05 & 0.15 & 0.14 & 0.15 & 0.07 & 0.17 & 0.08 & 0.07 \\
\hline Education & 0.09 & 0.09 & 0.1 & 0.08 & 0.09 & 0.1 & 0.1 & 0.08 \\
\hline Income & $0.20 * *$ & 0.13 & 0.13 & $0.16^{*}$ & $0.16^{*}$ & 0.14 & 0.19 & 0.19 \\
\hline Mobile shopping & & $0.56^{* *}$ & & & & & & \\
\hline Convenience & & & $0.54 * *$ & & & & & \\
\hline Personalization & & & & $0.49 * *$ & & & & \\
\hline Fun & & & & & $0.48 * *$ & & & \\
\hline Socialization & & & & & & $0.48^{* *}$ & & \\
\hline Instantiation & & & & & & & $0.50 * *$ & \\
\hline Situationalization & & & & & & & & $0.42 *$ \\
\hline
\end{tabular}


Cont. to Table 2

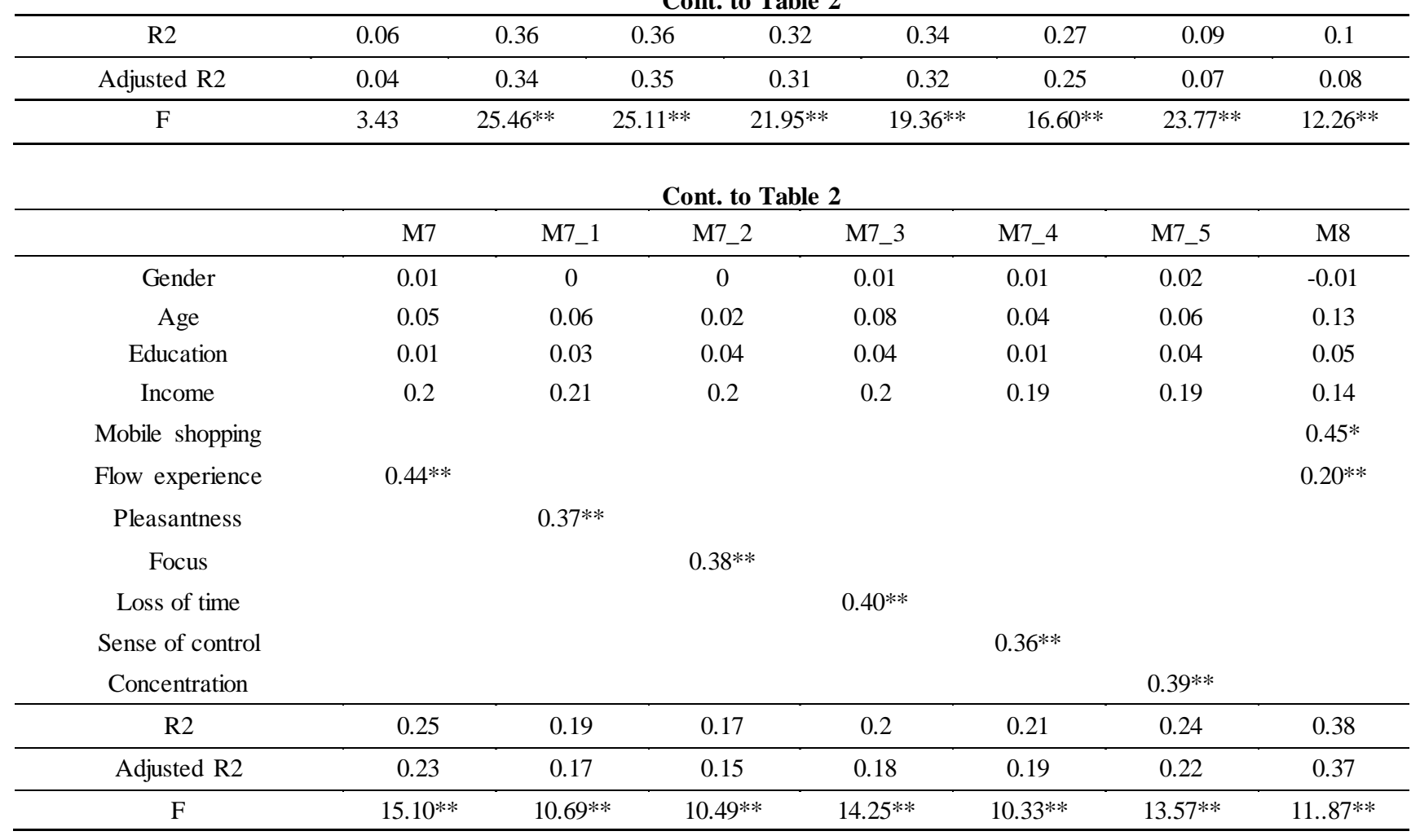

\section{Conclusions and Shortcomings}

The flow experience mediates in mobile shopping and consumer purchase intention. The consumer purchase intention mediates in flow experience and impulsive purchase. Between the mobile shopping and the impulse purchaser, chain mediation sets up. It is not existed that impulsive trait regulates the relationship between purchase intention and impulsive purchase. There are still many shortcomings in this study. Structural equation modeling may simplify the empirical research process.

Table 3 Regression analysis of impulsive buying behavior as a dependent variables

\begin{tabular}{|c|c|c|c|c|c|c|c|c|}
\hline & M9 & M10 & M10_1 & M10_2 & M10_3 & M10_4 & M10_5 & M10_6 \\
\hline Gender & 0.02 & 0 & 0 & -0.01 & 0.02 & -0.01 & 0.01 & 0.02 \\
\hline Age & 0.07 & 0.16 & 0.14 & 0.15 & 0.08 & 0.18 & 0.09 & 0.09 \\
\hline Education & 0.03 & 0.03 & 0.04 & 0.03 & 0.03 & 0.04 & 0.04 & 0.01 \\
\hline Income & 0.05 & -0.01 & -0.01 & 0.02 & 0.01 & -0.01 & 0.04 & 0.04 \\
\hline Mobile shopping & & $0.54 * *$ & & & & & & \\
\hline Convenience & & & $0.47 * *$ & & & & & \\
\hline Personalization & & & & $0.46^{* *}$ & & & & \\
\hline Fun & & & & & $0.51^{* *}$ & & & \\
\hline Socialization & & & & & & $0.45^{* *}$ & & \\
\hline Instantiation & & & & & & & $0.39 * *$ & \\
\hline Situationalization & & & & & & & & $0.31^{* *}$ \\
\hline $\mathrm{R} 2$ & 0.01 & 0.29 & 0.22 & 0.21 & 0.27 & 0.2 & 0.05 & 0.1 \\
\hline Adjusted R2 & -0.01 & 0.27 & 0.21 & 0.2 & 0.26 & 0.19 & 0.02 & 0.09 \\
\hline $\mathrm{F}$ & 0.52 & $18.41^{* *}$ & $13.27 * *$ & $12.42 * *$ & $17.29 * *$ & $11.72 * *$ & $2.18^{* *}$ & $5.39 * *$ \\
\hline
\end{tabular}


Cont. to Table 3

\begin{tabular}{|c|c|c|c|c|c|c|c|c|c|c|}
\hline & M11 & M11_1 & M11_2 & M11_3 & M11_4 & M11_5 & M12 & M13 & M14 & M15 \\
\hline Gender & 0.03 & 0.02 & 0.02 & 0.03 & 0.03 & 0.04 & 0.02 & 0.02 & 0.02 & 0.02 \\
\hline Age & 0.07 & 0.07 & 0.04 & 0.09 & 0.06 & 0.07 & 0.04 & 0.04 & 0.04 & 0.04 \\
\hline Education & -0.03 & -0.02 & -0.01 & -0.01 & -0.04 & -0.01 & -0.02 & -0.04 & -0.04 & -0.04 \\
\hline Income & 0.05 & 0.06 & 0.06 & 0.05 & 0.04 & 0.05 & -0.06 & -0.05 & -0.05 & -0.05 \\
\hline Flow experience & $0.37 * *$ & & & & & & & $0.14^{* *}$ & 0.14 & 0.14 \\
\hline Pleasantness & & $0.36^{* *}$ & & & & & & & & \\
\hline Focus & & & $0.27 * *$ & & & & & & & \\
\hline Loss of time & & & & $0.36 * *$ & & & & & & \\
\hline Sense of control & & & & & $0.30 * *$ & & & & & \\
\hline Concentration & & & & & & $0.34 * *$ & & & & \\
\hline Purchase intention & & & & & & & $0.58 * *$ & $0.51^{* *}$ & $0.51^{* *}$ & $0.49 * *$ \\
\hline Impulse buying behavior & & & & & & & & & 0.06 & 0.05 \\
\hline $\begin{array}{c}\text { Purchase } \\
\text { intention*impulsive trait }\end{array}$ & & & & & & & & & & 0.13 \\
\hline $\mathrm{R} 2$ & 0.14 & 0.1 & 0.08 & 0.12 & 0.13 & 0.12 & 0.32 & 0.34 & 0.34 & 0.34 \\
\hline Adjusted R2 & 0.12 & 0.08 & 0.06 & 0.1 & 0.11 & 0.1 & 0.31 & 0.32 & 0.32 & 0.31 \\
\hline F & $7.51^{* *}$ & $6.86^{* *}$ & $4.10^{*}$ & $6.80 * *$ & $5.95^{* *}$ & $6.23 * *$ & $21.79 * *$ & $19.39^{* *}$ & $16.55^{* *}$ & $14.48^{* *}$ \\
\hline
\end{tabular}

Table 4 Multiple mediation effect test

\begin{tabular}{cccc}
\hline \multirow{2}{*}{ Path } & \multirow{2}{*}{ Estimated value } & \multicolumn{2}{c}{ 95\% Confidence interval } \\
& & Lower limit & Upper limit \\
\hline A1B1 & 0.001 & 0.013 & 0.028 \\
A2B2 & 0.000 & 0.021 & 0.026 \\
A1D1B2 & 0.000 & 0.001 & 0.005 \\
TOTALIND & 0.002 & 0.027 & 0.035 \\
TOTAL & 0.286 & 0.460 & 0.099 \\
\hline
\end{tabular}

\section{Acknowledgment}

The study supported by “the Fundamental Research Funds for the Centre Universities”(Project approval number is 2018-2y-020 in School of management, WUT)

\section{References}

[1] Donthu N, Garcia A. “The Internet shopper” Journal of Advertising Research, 1999, 39(3):52-58.

[2] Lu Yi. "Research on Influence of Mobile Shopping Scene Characteristics on Consumers' Purchase Intention” unpublished

[3] Wang Lanqi. "Research on network consumption behaviour based on flow experience” unpublished

[4] Shang Xutong. "Research on Formation Mechanism of Consumer Online Impulsive Buying Behaviour" unpublished

[5] Wu Xiaomei. "Effects of Website Characteristics on Impulse Buying: Based on the Perspective of Flow Experience” Finance \& Trade Economics, 2014, 35(6):111-121

[6] Zhang X, Prybutok V R, Chang E K, et al. "The Role of Impulsiveness in a TAM-Based Online Purchasing Behaviou” IGI Global, 2006. 